\title{
Proton Conductivity of Mesoporous Silica Incorporated with Phosphorus under High Water Vapor Pressures up to $150^{\circ} \mathrm{C}$
}

\author{
Satoshi SUZUKI, Yoichiro NOZAKI, ${ }^{*}$ Toyoki OKUMURA* and Masaru MIYAYAMA \\ Research Center for Advanced Science and Technology, The University of Tokyo, 4-6-1, Komaba, Meguro-ku, Tokyo 153-8904 \\ *Department of Industrial Chemistry, Faculty of Engineering, Tokyo University of Science, 1-3, Kagurazaka, Shinjuku-ku, Tokyo 162-8601
}

\author{
$150^{\circ} \mathrm{C}$ ま゙の高水蒸気分圧下におけるリン複合メソ多孔シリカのプロトン導電性 \\ 鈴木智史 · 野崎洋一郎* · 奥村豊旗* ·宮山 勝 \\ 東京大学先端科学技術研究センター, 153-8904 東京都目黒区駒場 4-6-1 \\ *東京理科大学工学部工業化学科, 162-8601 東京都新宿区神楽坂 1-3
}

\begin{abstract}
Silica mesoporous structures incorporated with phosphorus were prepared and their proton conductivity was evaluated at temperatures of up to $150^{\circ} \mathrm{C}$ under saturated or controlled water vapor pressure. The fixing of phosphoric acid through heat treatment after forming the mesostructure had a limited effect on the improvement in proton conductivity only in a relatively low-temperature region. The incorporation of phosphorus during mesoporous silica formation decreased the surface area but was effective in improving proton conductivity. A sample with a low $\mathrm{P} / \mathrm{Si}$ atomic ratio of 0.07 showed the highest proton conductivity above $10^{-2} \mathrm{Scm}^{-1}$ at 100 to $120^{\circ} \mathrm{C}$ under saturated water vapor pressure. A sample with a high $\mathrm{P} / \mathrm{Si}$ atomic ratio of 0.25 showed relatively high conductivities being maintained even at low relative humidity at $150^{\circ} \mathrm{C}$. An adequate phosphorus concentration and a large surface area were found necessary for high and humidity-independent proton conductivity in mesoporous silica.

[Received November 10, 2005; Accepted February 16, 2006]
\end{abstract}

Key-words : Proton conduction, Composite electrolyte, Self-assemble method mesoporous material, Fuel cell

\section{Introduction}

Recently, fuel cells using a polymer electrolyte (PEFCs) have been developed as a power source for electric cars and in cogeneration systems for home use. One of the most widely used electrolytes in these fuel cells is perfluorosulfonic acid (Nafion, developed by Dupont Co.). Nafion is used only below $100^{\circ} \mathrm{C}$ due to heat-resistance limitations. Since the platinum catalyst used in PEFC electrodes is degraded by the carbon monoxide contained in the fuel gas, the concentration of carbon monoxide in the fuel gas has to be reduced below 10 $\mathrm{ppm}$. If PEFCs can be operated at intermediate temperatures above $100^{\circ} \mathrm{C}$, the degradation of platinum catalysts is markedly suppressed. In addition, a high efficiency of proton generation and easy management of water in the inlet and outlet gases can be expected in intermediate-temperature operation. Therefore, proton conductors with a high conductivity and a good heat resistance are desired, and proton conductors made of inorganic materials are promising candidates.

Most of the reported inorganic materials showing high proton conductivities at low and intermediate temperatures below $200^{\circ} \mathrm{C}$ use surface proton conduction on porous $\mathrm{SiO}_{2}$ and glass. ${ }^{1-13)}$ Proton conduction occurs through surface adsorbed water and condensed water in pores. The water vapor condenses in pores through capillary condensation, and this occurs at lower water vapor pressures for smaller pores. Accordingly, a porous microstructure with a high surface area and small pores is favorable for high proton conductivity. From the restrictions of proton diffusion by water molecules confined in very small pores, it has been demonstrated that high conductivity is observed in porous silica glass with pores of $4-5 \mathrm{~nm}$ in diameter. ${ }^{1,2)}$ Proton conductivity of silica xerogel has been reported to be $4 \times 10^{-3} \mathrm{~S} / \mathrm{cm}$ at $92^{\circ} \mathrm{C}$ under a relative humidity $(\mathrm{RH})$ of $81 \% \cdot{ }^{3)}$ Mesoporous silica, synthesized by the self-assembly method using surfactants as a template, has a large surface area and an uniform pore diameter of several nm. ${ }^{14)-16)}$ Thus, the mesoporous silica is a promising candidate proton conductor using surface conduction. The proton conductivities of mesoporous silica have been reported to be $10^{-5} \mathrm{~S} / \mathrm{cm}$ at $50^{\circ} \mathrm{C}$ in $90 \% \mathrm{RH}^{4)}$ and $2 \times$ $10^{-3} \mathrm{~S} / \mathrm{cm}$ at $50^{\circ} \mathrm{C}$ in $80 \% \mathrm{RH}^{2)}$

The protons are generated through the dissociation of adsorbed and condensed water. Therefore, an increase in the acidity of the material surface by introducing strong acids is effective to enhance water dissociation and proton conduction. ${ }^{1,5)-13)}$ The phosphoric ${ }^{1), 5)-12)}$ and sulfonic ${ }^{13)}$ acid groups are generally used for silica derived materials. In addition, strong acidity also contributes to retaining water molecules under low water vapor pressures. ${ }^{3)}$ This leads to a high proton conductivity under low water vapor pressures. The proton conductivities of $\mathrm{P}_{2} \mathrm{O}_{5}-\mathrm{SiO}_{2}$ glass have been reported to be $2 \times$ $10^{-2} \mathrm{~S} / \mathrm{cm}$ at $30^{\circ} \mathrm{C}$ in $80-90 \% \mathrm{RH},{ }^{1,5)} 3 \times 10^{-2} \mathrm{~S} / \mathrm{cm}$ at $50^{\circ} \mathrm{C}$ in $70 \% \mathrm{RH}^{6}{ }^{6}$ The proton conductivity of the phosphosilicate gels have been reported to be $10^{-2} \mathrm{~S} / \mathrm{cm}$ at $130-150^{\circ} \mathrm{C}$ in $0.4-0.7 \% \mathrm{RH},{ }^{7,8)} 5.5 \times 10^{-3} \mathrm{~S} / \mathrm{cm}$ at $85^{\circ} \mathrm{C}$ under an $\mathrm{Ar}$ atmosphere, ${ }^{9)} 2 \times 10^{-4} \mathrm{~S} / \mathrm{cm}$ at $150^{\circ} \mathrm{C}$ in $0.4 \% \mathrm{RH}$ for a phosphosilicate gel and polyimide composite. ${ }^{10)}$ If the phosphorous element can be fixed on the surface or incorporated into the mesoporous silica framework, a high proton conductivity can be expected in the intermediate-temperature region and in wide water vapor pressure region. The proton conductivities of mesoporous silica incorporated with phosphoric acid have been reported to be about $10^{-3} \mathrm{~S} / \mathrm{cm}$ and at $80^{\circ} \mathrm{C}$ in $70 \% \mathrm{RH}^{1}{ }^{11)}{ }^{12)}$ However, there have been no report as yet on the proton conductivity of mesoporous silica incorporated with phosphoric acid under intermediate temperature region up to $150^{\circ} \mathrm{C}$ under saturated water vapor pressure.

In the present study, we examined the proton conductivity of mesoporous silica at temperatures of up to $150^{\circ} \mathrm{C}$ and under 
controlled water vapor pressures up to saturated water vapor pressure. The samples were incorporated with phosphorous element using two methods; one method involves surface modification by heat treatment with phosphoric acid, and the other involves the preparation of mesoporous silica using starting materials with trimethylphosphate (TMOP) added as a phosphorous precursor. The proton conductivity of mesoporous silica was then evaluated up to $150^{\circ} \mathrm{C}$ at controlled water vapor pressures.

\section{Experimental}

Mesoporous silica materials were prepared as follows: ${ }^{17)}$ hexadecyltrimethylammonium bromide (CTAB) was dissolved in water, and an ammonium solution was added. Then tetraethyl-orthosilicate (TEOS) was added and the solution was stirred for $24 \mathrm{~h}$. The molar ratio of the starting materials was TEOS : $\mathrm{H}_{2} \mathrm{O}: \mathrm{CTAB}: \mathrm{NH}_{3}=1: 126: 0.15: 1.64$. The precipitate was filtered and calcined at $550^{\circ} \mathrm{C}$ for $5 \mathrm{~h}$. The resulting powder sample, which did not contain phosphorus, was denoted as sample SPad(-). Mesoporous silica powder (sample SPad $(-)$ ) and an excess amount of $85 \%$ phosphoric acid aqueous solution were mixed, and the mixture was dried by evacuating for $30 \mathrm{~min}$ to a pressure of $40 \mathrm{~Pa}$. Then the sample was maintained under a vacuum for $24 \mathrm{~h}$. This sample was denoted as sample $\operatorname{SPad}(20)$. Sample SPad (150) was prepared by heating sample $\operatorname{SPad}(20)$ at $150^{\circ} \mathrm{C}$ for $30 \mathrm{~min}$, and sample $\operatorname{SPad}(550)$ by heating sample $\operatorname{SPad}(20)$ at $550^{\circ} \mathrm{C}$ for $30 \mathrm{~min}$.

SPin group samples were also prepared as follows: TEOS, $\mathrm{H}_{2} \mathrm{O}, \mathrm{CTAB}, \mathrm{NH}_{3}$ and TMOP were mixed, and the precipitate obtained was filtered and calcined at $450^{\circ} \mathrm{C}$ for $3 \mathrm{~h}$. The samples with molar ratios of TMOP/TEOS (in starting materials) of $0,0.1,0.2$ and 0.5 were denoted as samples $\operatorname{SPin}(0), \operatorname{SPin}$ (0.1), SPin (0.2) and SPin (0.5), respectively. Abbreviated names and preparation conditions of the samples are shown in Table 1.

The structures of the samples were observed using low-angle X-ray diffraction analysis (RINT2500V, RIGAKU). The surface area and pore size distribution of the samples were measured by the nitrogen adsorption-desorption method (Tristar3000, Shimadzu). The molar ratio between the silicon and phosphorus of the sample SPin group was measured by inductively coupled plasma atomic emission spectrometry (ICP-AES). Infrared spectra were obtained between wave numbers of 4000 and $400 \mathrm{~cm}^{-1}$ for the sample SPin group. Each powder sample was milled with a fourfold weight of potassium bromide and formed into pellets by uniaxial pressing. Sample pellets for electrical measurement were prepared from each powder sample by uniaxial pressing at $230 \mathrm{MPa}$. Each pellet had a diameter of $4 \mathrm{~mm}$ and a thickness of $1 \mathrm{~mm}$. Gold electrodes were fabricated by ion sputtering on the top and bottom surfaces of the pellets. The conductivity of the pellets was measured using the AC impedance method in a frequency range of $5 \mathrm{~Hz}-13 \mathrm{MHz}$ for pellets placed in a stainless steel vessel, which is pressure-resistant up to $0.7 \mathrm{MPa}$. The water vapor pressure was controlled by heating the vessel and by adjusting the leak valve. The electrical measurements were conducted for samples put at a fixed temperature and atmosphere for $30 \mathrm{~min}$. For the measurement of temperature dependence of conductivity, samples were exposed to air at room temperature for $12 \mathrm{~h}$. during the first and second run.

\section{Results and discussion}

The XRD pattern of sample SPad (-) is shown in Fig. 1. Four peaks were observed at $2.3^{\circ}, 3.9^{\circ}, 4.5^{\circ}$, and $6.1^{\circ}$; these
Table 1. Abbreviated Names of the Samples

\begin{tabular}{ccccc}
\hline & $\begin{array}{c}\text { Precursor of } \\
\text { phosphorus }\end{array}$ & $\begin{array}{c}\text { Atomic } \\
\text { ratio of }\end{array}$ & $\begin{array}{c}\text { Calcination } \\
\text { temperature }\end{array}$ & $\begin{array}{c}\text { Heat } \\
\text { treatment }\end{array}$ \\
\hline SPad(-) & None & - & 550 & None \\
SPad(20) & $\begin{array}{c}\text { Phosphoric } \\
\text { acid }\end{array}$ & - & 550 & 20 \\
& $\begin{array}{c}\text { Phosphoric } \\
\text { acid }\end{array}$ & - & 550 & 150 \\
SPad(150) & $\begin{array}{c}\text { Phosphoric } \\
\text { acid }\end{array}$ & - & 550 & 550 \\
SPad(550) & TMOP & 0 & 450 & None \\
\hline SPin(0) & TMOP & 0.1 & 450 & None \\
SPin(0.1) & TMOP & 0.2 & 450 & None \\
SPin(0.2) & TMOP & 0.5 & 450 & None \\
SPin(0.5) & & & &
\end{tabular}

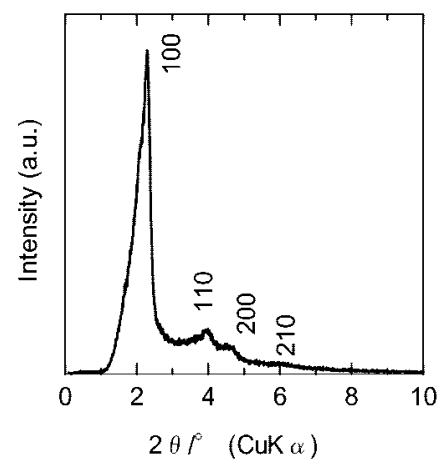

Fig. 1. X-ray diffraction pattern of sample $\operatorname{SPad}(0)$.

four peaks can be, respectively, indexed as the (100), (110), (200), and (210) reflections of a typical 2D hexagonal structure. ${ }^{17)}$ The $d$ value of (100) was estimated to be $3.9 \mathrm{~nm}$. The pore diameter of sample SPad(-) was $3.2 \mathrm{~nm}$ and the pore volume was $1.3 \mathrm{~cm}^{3} / \mathrm{g}$, estimated from nitrogen adsorption measurement using the $\mathrm{BJH}$ method. ${ }^{18)}$ The surface area of the sample was $1100 \mathrm{~m}^{2} / \mathrm{g}$, estimated using the BET method. The intensity of the low-angle XRD peaks decreased markedly in samples $\operatorname{SPad}(20)$ and $\operatorname{SPad}(150)$, and those peaks were not observed in sample $\operatorname{SPad}(550)$. The surface area of sample $\operatorname{SPad}(550)$ was as low as $6.6 \mathrm{~m}^{2} / \mathrm{g}$. In addition, weak XRD peaks of $\mathrm{SiP}_{2} \mathrm{O}_{7}$ were observed in high angle region for sample SPad (550). These indicate that the mesostructure had collapsed through the action of the phosphoric acid and following heat treatment.

The results of the XRD measurement of samples SPin (0) to SPin (0.5) are shown in Fig. 2. The main peak (100) was broadened with an increase in the amount of TMOP. This indicates that the periodicity of the mesosize region becomes vague with the addition of a high amount of TMOP. The (100) peak positions for samples SPin (0) to SPin (0.2) were located at 1.8 to $2.0^{\circ}$, indicating $d$ values of 4.5 to $4.9 \mathrm{~nm}$. The peak of SPin (0.5) was very broad for estimating the $d$ value, and the dependence of the $d$ value on TMOP concentration was not evident. The $d$ values of samples $\operatorname{SPin}(0)$ to SPin (0.2) were larger than that of sample SPad (-). This is due to the lower calcination temperature $\left(450^{\circ} \mathrm{C}\right)$ of samples $\operatorname{SPin}(0)$ to $\operatorname{SPin}(0.2)$ than that of sample $\operatorname{SPad}(-)\left(550^{\circ} \mathrm{C}\right)$. 


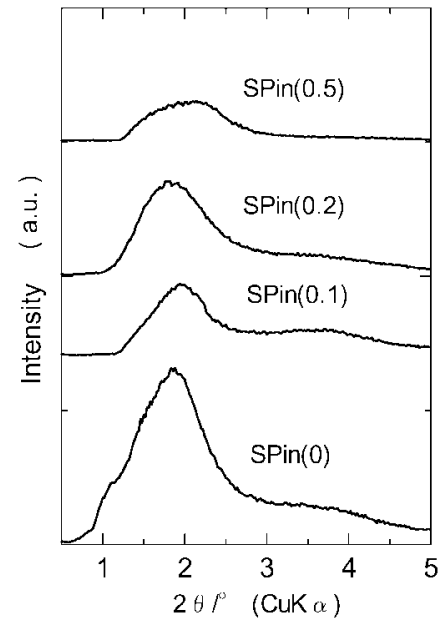

Fig. 2. X-ray diffraction patterns of samples $\operatorname{SPin}(0)$ to $\operatorname{SPin}(0.5)$ after calcination. (a)
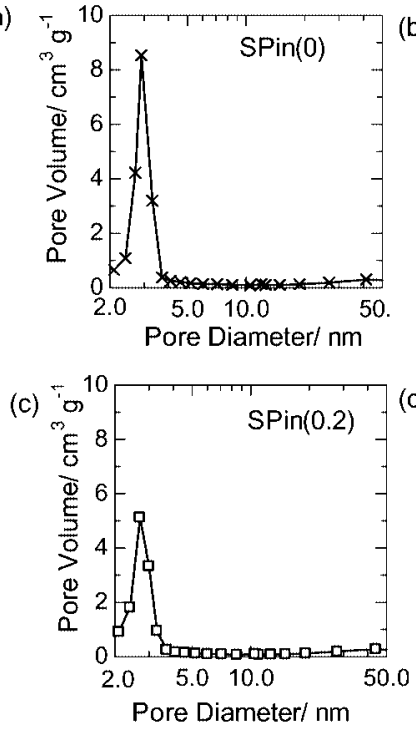
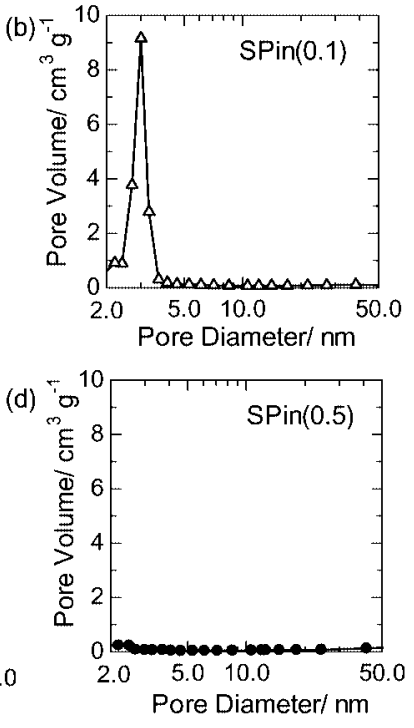

Fig. 3. Pore size distribution of samples $\operatorname{SPin}(0)$ to $\operatorname{SPin}(0.5)$.

The pore volume distributions of samples SPin $(0)$ to SPin $(0.5)$ are shown in Fig. 3. The pore diameters estimated from peak positions were $2.9,3.0$, and $2.7 \mathrm{~nm}$ for sample $\operatorname{SPin}(0)$, $\operatorname{SPin}(0.1)$, and $\operatorname{SPin}(0.2)$, respectively. The pore diameter of sample SPin $(0.5)$ was not clear due to the presence of a broad peak. The diameters of samples $\operatorname{SPin}(0), \operatorname{SPin}(0.1)$, and SPin (0.2) were almost the same as that of the surfactant micelles, indicating that the micelle formation of surfactants is not markedly affected by the amount of TMOP. The pore volume and relative surface area of samples are shown in Table 2. The pore volume and surface area decreased with increasing amounts of TMOP. Sample SPin (0.5) had very small values. The surface area of sample SPin $(0.5)$ was only one-tenth that of sample SPin $(0)$. This tendency corresponds to that of the broadening of XRD peaks. Two reasons for this can be considered: one is the inhibition of the organization of surfactants with the precursor of silica during mesostructure formation with TMOP; the other is the cutting of the silica framework by the incorporated phosphorus during calcination. However, it is not clear which phenomenon is predominant.
Table 2. $\mathrm{P} / \mathrm{Si}$ Atomic Ratio, Pore Volume, and Specific Surface Area for Samples SPin $(0)$ to $\operatorname{SPin}(0.5)$

\begin{tabular}{ccccc}
\hline & $\begin{array}{c}\text { P/Si atomic } \\
\text { ratio of } \\
\text { starting }\end{array}$ & $\begin{array}{c}\text { P/Si atomic } \\
\text { ratio }\end{array}$ & $\begin{array}{c}\text { Pore } \\
\text { volume } /\end{array}$ & $\begin{array}{c}\text { Surface } \\
\text { area / }\end{array}$ \\
& 0 & 0 & 1.3 & 1100 \\
$\operatorname{SPin}(0)$ & 0.1 & 0.07 & 1.0 & 940 \\
$\operatorname{SPin}(0.1)$ & 0.2 & 0.16 & 0.9 & 760 \\
$\operatorname{SPin}(0.2)$ & 0.5 & 0.25 & 0.3 & 110 \\
$\operatorname{SPin}(0.5)$ & & & $\mathrm{cm}^{3} \mathrm{~g}^{-1}$ \\
\hline
\end{tabular}

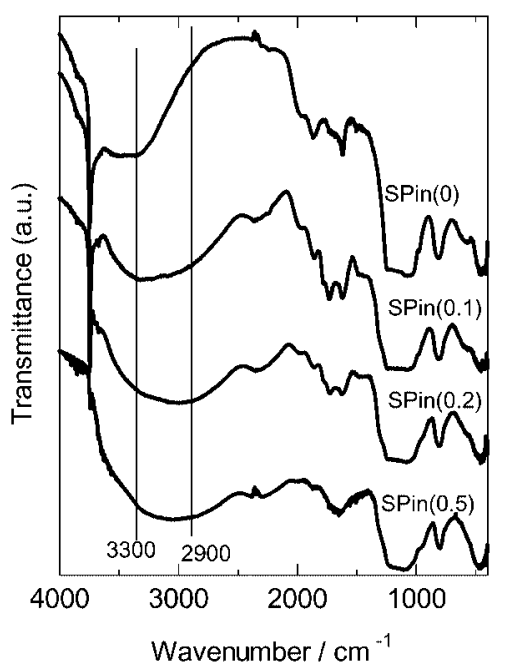

Fig. 4. FT-IR spectra of samples $\operatorname{Spin}(0)$ to $\operatorname{SPin}(0.5)$.

The atomic ratios of $\mathrm{P} / \mathrm{Si}$ of the sample SPin group are shown in Table 2 . The $\mathrm{P} / \mathrm{Si}$ ratios of the synthesized samples were smaller than those of the starting materials, and the difference in $\mathrm{P} / \mathrm{Si}$ ratio increased with $\mathrm{P}$ concentration in the starting materials. However, $50 \%$ phosphorus was incorporated in sample SPin (0.5).

The FT-IR spectra of the sample SPin group are shown in Fig. 4. The intensity of the absorption band peaking at 3300 $\mathrm{cm}^{-1}$ with a shoulder at approximately $2900 \mathrm{~cm}^{-1}$ was stronger in samples containing larger amounts of phosphorus. This peak and shoulder were attributed to $\mathrm{OH}$ stretching. ${ }^{5), 19)}$ This absorption peak with a shoulder was observed in the $\mathrm{P}_{2} \mathrm{O}_{5^{-}}$ $\mathrm{SiO}_{2}$ glass prepared by reacting TMOP and TEOS, but not in the glass. ${ }^{5}$ )

From the above results, phosphorus is incorporated into the silica network and its amount increases with the TMOP concentration in the starting material. However, the development of the mesostructure is inhibited by phosphorus, and pore volume and surface area decrease markedly with an increase in the amount of phosphorus, while the average pore diameter remained unchanged. This change in mesostructure also supports the incorporation of phosphorus in silica.

The temperature dependence of proton conductivity under saturated water vapor pressure for the sample SPad group is shown in Fig. 5. Samples $\operatorname{SPad}(20), \operatorname{SPad}(150)$, and SPad (550) showed a decrease in proton conductivity between the first and second measurements. In particular, the decrease was large for sample $\operatorname{SPad}(20)$. Since sample $\operatorname{SPad}(20)$ was dried 


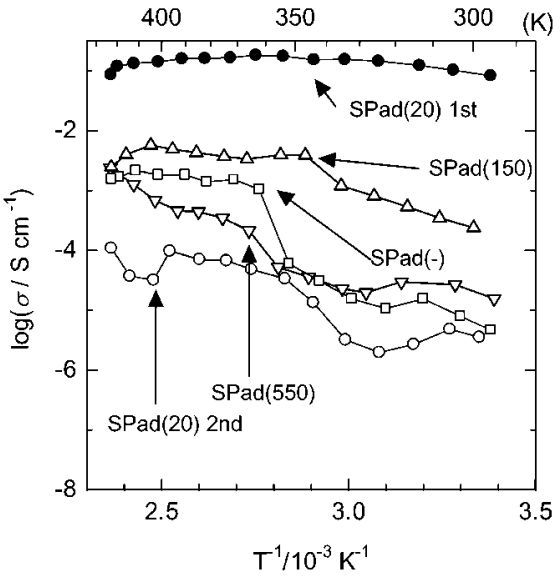

Fig. 5. Temperature dependence of conductivity for samples SPad (0) to $\operatorname{SPad}(550)$ under saturated water vapor pressure in the second measurement. The result in the first measurement is shown only for sample $\operatorname{SPad}(20)$.

at room temperature without heat treatment after mixing with phosphoric acid, phosphoric acid is not strongly bound on the surface of the silica. It is considered that phosphoric acid was eluted out under the saturated water vapor pressure. Therefore, the samples in the SPad group were compared in terms of proton conductivity in the second measurement. The conductivity of sample SPad (150) was higher than that of other samples, and reached $5.7 \times 10^{-3} \mathrm{~S} / \mathrm{cm}$ at $130^{\circ} \mathrm{C}$. This indicates that phosphoric acid was bound to the silica to some extent and this contributes to the increase in proton conductivity, but the enhancement of conductivity was limited to the relatively low-temperature region. Sample SPad (550) showed a lower conductivity than sample $\operatorname{SPad}(-)$. This is due to the decreased surface area of the mesostructure. The complex dependence on temperature of the conductivity in the second measurement may be caused by the effects of the eluted phosphoric acid, temperature-dependent adsorption/desorption of water molecules, and so on, but the exact cause is not clear at present.

The results in Fig. 5 show that the heat treatment of samples impregnated with phosphoric acid forms bonds between the silica surface and phosphorus to some extent, but that these bonds are weak and not sufficient to give a high and stable proton conductivity, even under saturated water vapor pressure.

The temperature dependence of proton conductivity for the samples in the SPin group under saturated water vapor pressure is shown in Fig. 6. The proton conductivities of samples $\operatorname{SPin}(0.1)$, SPin $(0.2)$, and SPin $(0.5)$ are higher than that of sample SPin $(0)$ at 20 to $150^{\circ} \mathrm{C}$. This shows that the phosphorus incorporated into the silica framework contributes to an improvement in proton conductivity over a wide temperature range. Samples SPin $(0.5)$, SPin (0.2), SPin (0.1), and SPin (0) showed higher proton conductivities in this order at $20^{\circ} \mathrm{C}$. This order corresponds to that of the phosphorus concentration. For samples $\operatorname{SPin}(0.5)$, SPin (0.2), and $\operatorname{SPin}(0.1)$, proton conductivity increased initially and then decreased with increasing temperature. The temperature at which the decrease in proton conductivity starts, decreased in order from samples $\operatorname{SPin}(0.5)$ to $\operatorname{SPin}(0.1)$. As a result, sample $\operatorname{SPin}(0.1)$ showed the highest conductivity (over $10^{-2} \mathrm{~S} / \mathrm{cm}$ ) in the sample SPin group at 100 to $120^{\circ} \mathrm{C}$. The mesoporous surface works as a proton-conduction path in these samples. As

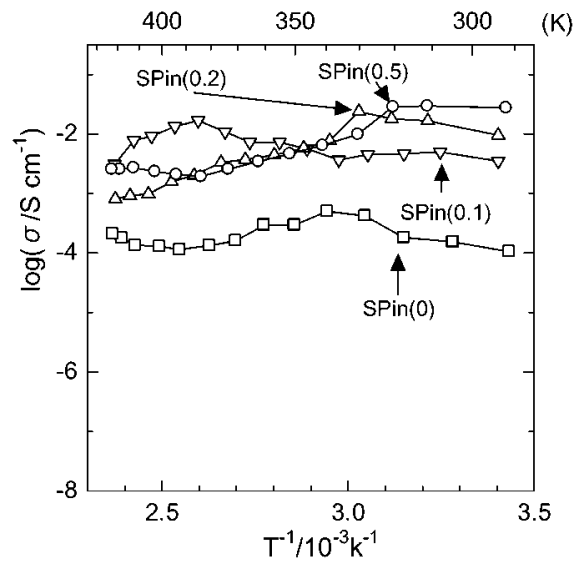

Fig. 6. Temperature dependence of conductivity for samples SPin (0) to SPin (0.5) under saturated water vapor pressure.

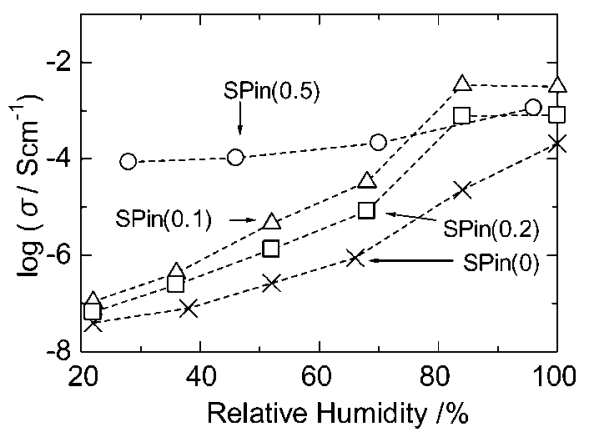

Fig. 7. Dependence of conductivity on relative humidity for samples $\operatorname{SPin}(0)$ to $\operatorname{SPin}(0.5)$ at $150^{\circ} \mathrm{C}$.

shown in Table 2, the pore volume and surface area are smaller in samples with a high phosphorus concentration. Samples with a high phosphorus concentration showed a high proton conductivity in the low-temperature region, but they also showed a decrease in proton conductivity at the early stage of heating. Probably, the effect of phosphorus on the increase in proton conductivity is weakened in the high-temperature region and the small surface area causes a marked decrease in proton conductivity. The high proton conductivity of sample SPin (0.1) in the high-temperature region is attributed to both the effects of the supply of protons by the phosphorus and the large surface area acting as a conduction path.

The humidity dependence of proton conductivity for the sample SPin group at $150^{\circ} \mathrm{C}$ is shown in Fig. 7. With decreasing humidity, the proton conductivity of sample SPin(0) decreased continuously but those of samples $\operatorname{SPin}(0.1)$ and SPin $(0.2)$ started to decrease at about $80 \% \mathrm{RH}$. At a low humidity of about $20 \%$, such proton conductivities were as low as $10^{-8}$ to $10^{-7} \mathrm{Scm}^{-1}$. However, the decrease in the proton conductivity of sample SPin $(0.5)$ was small, and a conductivity of $10^{-4} \mathrm{Scm}^{-1}$ was maintained at lower humidities. That is, the $\operatorname{SPin}(0.5)$ has a dry resistance to proton conductivity. The humidity dependence of conductivity of sample SPin (0.5) was similar to that of microporous phosphosilicate. ${ }^{2)}$ Sample SPin (0.5) had few mesopores and macropores, as show in Fig. 3, and therefore the surface area and pore volume of SPin $(0.5)$ was derived from its micropores with pore diameter below $2 \mathrm{~nm}$. Microporous phosphosilicates are reported to show 
high proton conductivity with little dependence on humidity, due to the capillary condensation of adsorbed water molecules occurring even at low humidities. ${ }^{2)}$ Also, for sample SPin $(0.5)$, the presence of a high concentration of phosphorus and micropores is responsible for the small humidity dependence of conductivity, although the conductivity value is not so high at $150^{\circ} \mathrm{C}$ due to the small surface area.

The results in Figs. 6 and 7 show that the incorporation of phosphorus is effective in improving proton conductivity in the temperature and humidity regions measured. The proton conductivity at low temperatures of below $50^{\circ} \mathrm{C}$ was larger in samples with a high phosphorus concentration. However, the incorporation of a high phosphorus concentration resulted in a decrease in proton conductivity on heating, probably due to the small surface area and small pore volume. As a result, sample $\mathrm{SPin}(0.1)$ with its low $\mathrm{P} / \mathrm{Si}$ atomic ratio of 0.07 showed the highest proton conductivity above $10^{-2} \mathrm{Scm}^{-1}$ at 100 to $120^{\circ} \mathrm{C}$. However, the sample with a high $\mathrm{P} / \mathrm{Si}$ atomic ratio of 0.25 maintained its proton conductivity at low relative humidities, which is due to the presence of micropores.

From these results, it can be assumed that a large surface area and higher pore volume contribute to a high conductivity at high humidities and the presence of micropores contributes to small humidity dependence of conductivity, under the presence of phosphorus. A high and humidity-independent proton conductivity can be expected in mesoporous silica even at $150^{\circ} \mathrm{C}$, if they are provided with a large surface area, smallsize pores, and an adequate phosphorus concentration.

\section{Summary}

The incorporation of phosphorus in mesoporous silica was conducted using two methods and the proton conductivity of such silica was evaluated up to $150^{\circ} \mathrm{C}$. The fixing of phosphoric acid by heat treatment at $150^{\circ} \mathrm{C}$ after forming the mesoporous structure improved proton conductivity, but the effect was limited to the relatively low-temperature region due to the weak bond of phosphorus and the decrease of surface area. The incorporation of phosphorus during mesoporous silica formation was effective in improving proton conductivity in the temperature and humidity regions examined. A sample with a low $\mathrm{P} / \mathrm{Si}$ atomic ratio of 0.07 showed the highest conductivity at above $10^{-2} \mathrm{Scm}^{-1}$ at 100 to $120^{\circ} \mathrm{C}$. The incorporation of a high phosphorus concentration results in decreases in surface area and proton conductivity at high temperatures, but a sample with a $\mathrm{P} / \mathrm{Si}$ atomic ratio of 0.25 maintained its proton conductivity even at low relative humidities at $150^{\circ} \mathrm{C}$. An adequate phosphorus concentration and a large surface area with small pores were found necessary for the high and humidity-independent proton conductivity of mesoporous silica in the intermediate-temperature region of up to $150^{\circ} \mathrm{C}$.

\section{References}

1) Daiko, Y., Kasuga, T. and Nogami, M., Chem. Mat., Vol. 14, pp. 4624-4627 (2002).

2) Daiko, Y., Kasuga, T. and Nogami, M., Microporous Mesoporous Mat., Vol. 69, pp. 149-155 (2004).

3) Vichi, F. M., Colomer, M. T. and Anderson, M. A., Electrochem. Solid-State Lett., Vol. 2, pp. 313-316 (1999).

4) Li, H. B. and Nogami, M., Adv. Mat., Vol. 14, pp. 912-914 (2002).

5) Nogami, M., Nagao, R., Wong, G., Kasuga, T. and Hayakawa, T., J. Phys. Chem. B, Vol. 103, pp. 9468-9472 (1999).

6) Nogami, M., Goto, Y., Tsurita, Y. and Kasuga, T., J. Am. Ceram. Soc., Vol. 84, pp. 2553-2556 (2001).

7) Matsuda, A., Kanzaki, T., Tadanaga, K., Tatsumisago, M. and Minami, T., Electrochim. Acta, Vol. 47, pp. 939-944 (2001).

8) Matsuda, A., Nono, Y., Tadanaga, K., Minami, T. and Tatsumisago, M., Solid State Ionics, Vol. 162, pp. 253-259 (2003).

9) Iwakura, C., Kumagae, K., Yoshiki, K., Nohara, S., Furukawa, N., Inoue, H., Minami, T., Tatsumisago, M. and Matsuda, A., Electrochim. Acta, Vol. 48, pp. 1499-1503 (2003).

10) Matsuda, A., Nakamoto, N., Tadanaga, K., Minami, T. and Tatsumisago, M., Solid State Ionics, Vol. 162, pp. 247-252 (2003).

11) Li, H. B. and Nogami, M., Chem. Commun., Vol. 2, pp. 236-237 (2003).

12) Nogami, M., Li, H. B., Daiko, Y. and Mitsuoka, T., J. Sol-Gel Sci. Tech., Vol. 32, pp. 185-188 (2004).

13) Mikhailenko, S., Desplantier-Giscard, D., Danumah, C. and Kaliaguine, S., Microporous Mesoporous Mat., Vol. 52, pp. 29-37 (2002).

14) Yanagisawa, T., Shimizu, T., Kuroda, K. and Kato, C., Bull. Chem. Soc. Jpn., Vol. 63, pp. 988-992 (1990).

15) Kresge, C. T., Leonowicz, M. E., Roth, W. J., Vartuli, J. C. and Beck, J. S., Nature, Vol. 359, pp. 710-712 (1992).

16) Beck, J. S., Vartuli, J. C., Roth, W. J., Leonowicz, M. E., Kresge, C. T., Schmitt, K. D., Chu, C. T. W., Olson, D. H., Sheppard, E. W., Mccullen, S. B., Higgins, J. B. and Schlenker, J. L., J. Am. Chem. Soc., Vol. 114, pp. 10834-10843 (1992).

17) Kumar, D., Schumacher, K., von Hohenesche, C. D. F., Grun, M. and Unger, K. K., Colliids. Surfaces A-Physicochem. Eng. Aspects, Vol. 187, pp. 109-116 (2001).

18) Barrett, E. P., Joyner, L. G. and Halenda, P. P., J. Am. Chem. Soc., Vol. 73, pp. 373-380 (1951).

19) Abe, Y., Shimakawa, H. and Hench, L. L., J. Non-Cryst. Solids, Vol. 51, pp. 357-365 (1982). 